THE SOLUBILITY OF THE NITRATES OF POTASSIUM, ETC.

779

\title{
LXXIX.-The Solubility of the Nitrates of Potassium, Barium, and Strontium, and the Stability of the Double Nitrate of Potassium and Barium.
}

By Alexander Findlay, Iowal Morgan and Ivor Prys Morris.

ON account of the relatively great electro-affinity of nitranion (nitrate ion), the formation of double nitrates is found to occur in but few cases; and with but one exception (the double nitrate of potassium and barium), these double nitrates are formed only when one of the metals has a valency greater than 2 . Thus we have the double nitrates of the rare-earth metals and of thorium (Meyer and Jacoby, Zeitsch. anorg. Chem., 1901, 33, 359).

The unexpected formation of a double nitrate of potassium and barium was first observed by Wallbridge (Amer. Chem. J., 1903, $30,154)$, whose analysis of the salt showed it to be anhydrous and to have the formula $2 \mathrm{KNO}_{3}, \mathrm{Ba}\left(\mathrm{NO}_{3}\right)_{2}$. This observation was confirmed in the following year by Foote (Amer. Chem. J., 1904, 32 , 251), who, by a solubility method, showed that "the double salt can form at $25^{\circ}$ under a moderately wide range of conditions; that is, it can form from solutions containing approximately from 15 to 27 per cent. of potassium nitrate, and from 6 to 2 per cent. of barium nitrate." Foote also pointed out that the salt cannot be recrystallised, but that the solution, if evaporated at $25^{\circ}$, would deposit at first crystals of barium nitrate.

By reason of the rather exceptional behaviour of barium nitrate, it was considered advisable to investigate this double-salt formation more fully, and more especially at different temperatures, in order to obtain a clearer idea of the stability of the double salt in contact with solution.

Similar experiments have also been carried out with potassium nitrate and strontium nitrate, but no evidence of the formation of a double salt has been obtained.

\section{Experimental.}

The single salts, in suitable weighed amounts and well powdered, were stirred with a weighed amount of water in a tube placed in a thermostat. At the end of a given time a quantity of the solution was withdrawn by means of a pipette to which a small filtering plug of cotton wool was attached. The weight of a given volume of the solution was then ascertained, and the total amount of salt in solution determined by evaporation and heating in an air-oven. The barium and strontium were determined gravimetric- 
ally as the sulphate and carbonate respectively, and the potassium nitrate was obtained by difference. Duplicate determinations of the solubility were made after stirring for two and for three (or four) hours respectively, the attainment of the saturation equilibrium being thereby controlled.

\section{A. Potassium Nitrate and Barium Nitrate.}

The salts employed were supplied by Kahlbaum, and were recrystallised before use. The results obtained are given in the following table, and are represented graphically in the accompanying figure.

\section{Solubility of Potassium Nitrate and Barium Nitrate.}

100 Grams of solution contain, in grams.

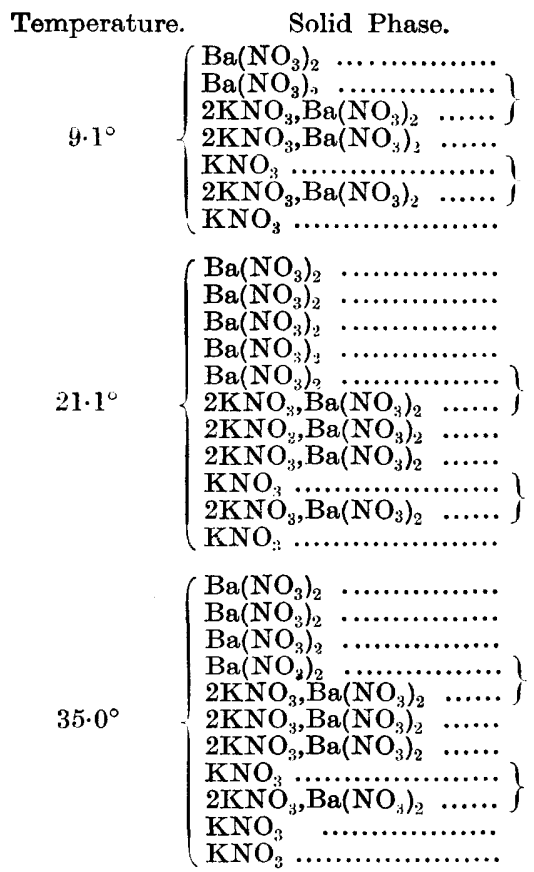

\begin{tabular}{|c|c|}
\hline $\begin{array}{c}\mathrm{KNO}_{3}, \\
-\end{array}$ & $\begin{array}{c}\mathrm{Ba}\left(\mathrm{NO}_{3}\right) \\
6.25\end{array}$ \\
\hline $8 \cdot 15$ & $4 \cdot 20$ \\
\hline $12 \cdot 02$ & 1.98 \\
\hline 16.80 & 0.98 \\
\hline $16 \cdot 76$ & - \\
\hline $\begin{array}{l}\overrightarrow{2 \cdot 12} \\
5 \cdot 98 \\
8 \cdot 47\end{array}$ & $\begin{array}{l}8 \cdot 46 \\
7 \cdot 47 \\
6 \cdot 35 \\
6 \cdot 06\end{array}$ \\
\hline $13 \cdot 24$ & $5 \cdot 98$ \\
\hline $\begin{array}{l}18 \cdot 24 \\
21 \cdot 47\end{array}$ & $\begin{array}{l}3 \cdot 35 \\
2 \cdot 30\end{array}$ \\
\hline $24 \cdot 86$ & $1 \cdot 76$ \\
\hline $24 \cdot 77$ & - \\
\hline $\begin{array}{r}\overline{12 \cdot 99} \\
17 \cdot 48\end{array}$ & $\begin{array}{r}11 \cdot 39 \\
8 \cdot 18 \\
8 \cdot 08\end{array}$ \\
\hline $19 \cdot 75$ & $8 \cdot 42$ \\
\hline $\begin{array}{l}24 \cdot 00 \\
26 \cdot 05\end{array}$ & $\begin{array}{l}5 \cdot 85 \\
5 \cdot 02\end{array}$ \\
\hline $34 \cdot 87$ & 3.02 \\
\hline $\begin{array}{l}34 \cdot 98 \\
35 \cdot 01\end{array}$ & $1 \cdot 77$ \\
\hline
\end{tabular}

The solubility values obtained by us show, on the whole, good agreement with previous determinations, although, in the case of barium nitrate, our values are rather lower than those obtained by Mulder (Landolt-Börnstein's "Tabellen"). The values for potassium nitrate are, however, in perfect harmony with the 
NITRATES OF POTASSIUM, BARIUM, AND STRONTIUM, ETC. 781

average values obtained by others (Comey's "Dictionary of Solubilities"). As regards the composition of the solutions in equilibrium with two solid phases, our values are in good agreement with the data obtained by Euler (Zeitsch. physikal. Chem., 1904, 49, 301) and by Foote (loc. cit.). Our analyses of the double salt, lastly, confirm entirely the formula given by Wallbridge (loc. cit.).

On examining the diagram of isothermals, one is struck at once by the very considerable range of stability of the double salt, and it is to be observed that this range increases at higher temperatures. Since, however, the line $O A$, which represents the relative amounts of potassium nitrate and barium nitrate in the double salt, cuts the curves for solutions in equilibrium with solid barium nitrate, it follows that at the temperatures investigated, and at higher temperatures, the double salt will, when brought in contact with water, deposit barium nitrate, and yield a solution relatively rich

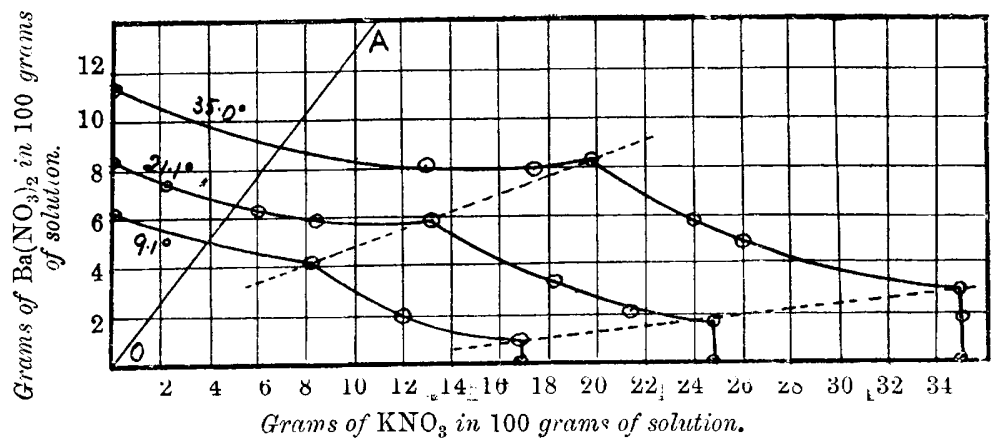

in potassium nitrate. The diagram shows, further, that it will be possible to crystallise the double salt only from solutions containing excess of potassium nitrate, and in which the relative proportions of that salt and barium nitrate are those represented by a point lying within the area bounded, above and below, by the dotted lines.

From the diagram it is also clear that the transition point, if such exists, for the double salt to the single salts must lie at lower temperatures, the transition interval commencing at the point where the upper dotted line cuts the line $O A$. Since this upper dotted line appears to be not straight, but convex, it is doubtful whether such intersection with the line $O A$ will occur at all. In this case, the double salt would be decomposed by water at all temperatures, and would behave, in this respect, analogously to carnallite (van't Hoff and Meyerhoffer, Zeitsch. physikal. Chem., 1899, 30, 64). 


\section{B. Potassium Nitrate and Strontium Nitrate.}

In the case of these salts, the solubilities have been determined at $20^{\circ}$ and at $40^{\circ}$, but at neither temperature was evidence of the formation of a double salt obtained. The isothermals in this case consist of two branches representing solutions in equilibrium with solid strontium nitrate and solid potassium nitrate respectively. At $20^{\circ}$ the strontium nitrate is hydrated $\left(4 \mathrm{H}_{2} \mathrm{O}\right)$, whereas at $40^{\circ}$ it is anhydrous. The solubility values are given in the following table.

Solubility of Potassium Nitrate and Strontium Nitrate.

100 Grams of solution contain,

Temperature.

Solid Phase.

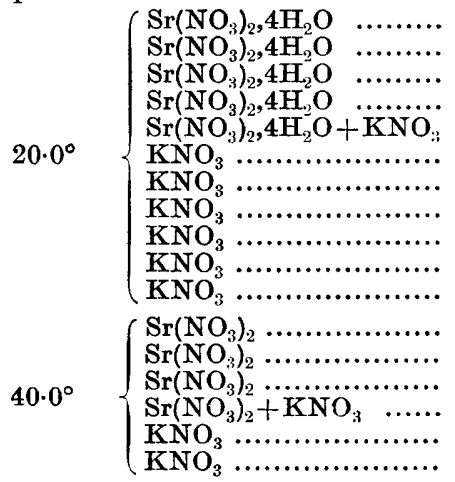

\begin{tabular}{|c|c|}
\hline $\mathrm{KNO}_{3}$. & $\mathrm{Sr}\left(\mathrm{NO}_{3}\right)_{2}$ \\
\hline & $41 \cdot 43$ \\
\hline $10 \cdot 00$ & $40 \cdot 70$ \\
\hline $12 \cdot 65$ & $41 \cdot 12$ \\
\hline $17 \cdot 56$ & $40 \cdot 37$ \\
\hline $19 \cdot 69$ & $39 \cdot 56$ \\
\hline $19 \cdot 49$ & 34.91 \\
\hline $19 \cdot 60$ & $31 \cdot 24$ \\
\hline $21 \cdot 01$ & $17 \cdot 10$ \\
\hline 21.70 & $9 \cdot 17$ \\
\hline $22 \cdot 90$ & $5 \cdot 49$ \\
\hline $24 \cdot 27$ & - \\
\hline - & $47.7 *$ \\
\hline $11 \cdot 19$ & $44 \cdot 19$ \\
\hline $22 \cdot 50$ & $40 \cdot 22$ \\
\hline 26.90 & $38 \cdot 52$ \\
\hline $30 \cdot 26$ & $23 \cdot 70$ \\
\hline $39.0^{*}$ & - \\
\hline
\end{tabular}

* These numbers are taken from the table of average values given in Comey's "Dictionary of Solubilities."

The Edward Davies Chemical Laboratories, University College of Walis, ABERYSTWYTH. 